We thank Dr Martin Edwards (Novo UK Ltd) and Mrs Linda McDonald for their help in the preparation of this manuscript.

1 Tunbridge WMG. Factors contributing to deaths of diabetics under fifty years of age. Lancet 1981;ii:569-72.

2 Casparie AF, Elving LD. Severe hypoglycemia in diabetic patients: frequency, causes, prevention. Diabetes Care 1985;8 (2): 141-5.

3 Potter J, Clarke P, Gale EAM, Dave SH, Tattersall RB. Insulin induced hypoglycaemia in an accident and emergency department: the tip of an iceberg? Br Med $\mathcal{F}$ 1982;285:1180-2.

4 Elrick H, Witten TA, Arai Y. Glucagon treatment of insulin reactions. N Engl f Med 1958;258: 476-80.

5 Mulhauser I, Koch J, Berger M. Pharmacokinetics and bioavailability of injected glucagon: differences between intramuscular, subcutaneous and intravenous administration. Diabetes Care $1985,8(1): 39-42$.

(Accepted 20 May 1986)

Diabetic and Dietetic Department, Royal Infirmary, Edinburgh EH3 9YW

D M MATTHEWS, MRCP, senior registrar

A W PATRICK, MRCP, registrar

D A COLLIER, MRCP, registrar

H A KELLETT, MRCP, lecture

J M STEEL, FRCPE, associate specialist

B F CLARKE, FRCPE, consultant physician

Medical Statistics and Computing Unit, University Medical School, Edinburgh

C C A MACINTYRE, MSC, research associate

Correspondence to: Dr Matthews.

\section{The "last joint" syndrome in ankylosing spondylitis}

Nerve root compression is a rare complication of ankylosing spondylitis. ${ }^{\prime}$ We describe a case in which bony encroachment into the intervertebral foramina at the only unfused segments in the cervical and lumbar spine (the "last joints") resulted in recurrent nerve root compression. Tomography showed the presence of osteophytes, which were removed surgically, resulting in complete relief of symptoms.

\section{Case report}

A 31 year old man with a 10 year history of ankylosing spondylitis was first seen in 1977. He had a rigid thoracolumbar spine with a dorsal kyphosis but still had some painful movement in his neck.

In November 1980 he complained of burning pain in both thighs. There was minor blunting of pain sensation in the anterior aspect of the right thigh. Tomography showed a large posterior osteophyte arising from the posterior articulation and encroaching on the L3-4 intervertebral foramen. This was removed surgically with excellent pain relief. All the lumbar spinal joints other than those at L 3-4 had fused.

In October 1981 he was readmitted with pain and sensory loss in the anterior left thigh, weakness and wasting of the left quadriceps, and a diminished left knee jerk. Tomography showed a large osteophyte growing forward into the left L3-4

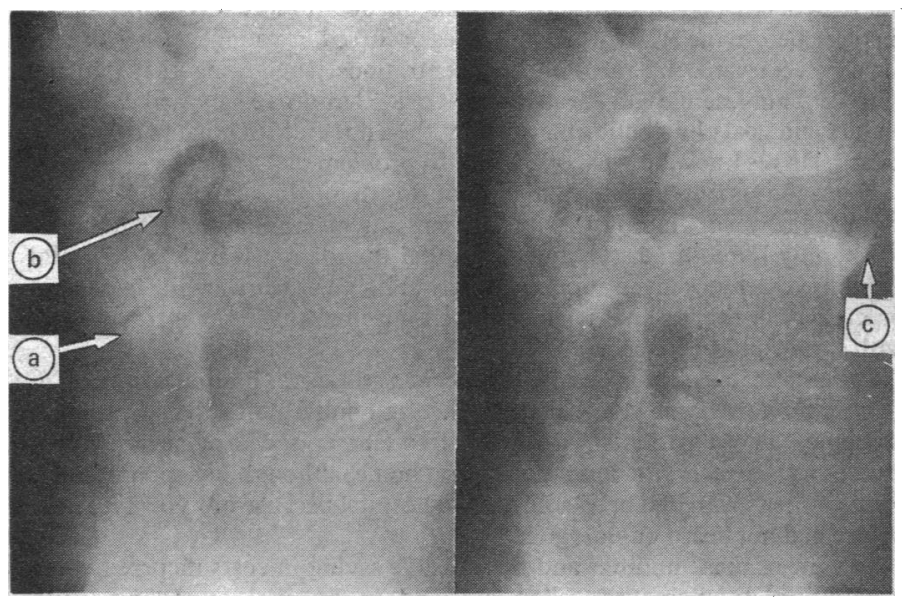

Left lateral tomograms at L3-4 showing: (a) open L3-4 apophyseal joint; (b large osteophyte arising from the L3-4 apophyseal joint; (c) osteophyte at 1 anterior margin of the $\mathrm{L} 4$ vertebral body. foramen. At operation the L3 nerve root was found trapped between the lower border of the pedicle laterally and the osteophyte medially. The osteophyte was removed, and the symptoms and signs rapidly resolved.

He remained well until March 1983, when he developed shooting pains down both arms, brought on by neck movement, and parasthesiae in the medial three fingers of the left hand. Oblique films of the cervical spine showed bilateral encroachment by an osteophyte on the C3-4 intervertebral foramina, with the left side affected more than the right. Severe osteoarthritic change was evident at the apophyseal joints, which were open. All other levels in the cervical spine except the occipitoatlantic joint were fused. An anterior cervical discectomy with fusion resulted in rapid and complete relief of symptoms.

In October 1984 he had a recurrence of neurological signs in the right thigh. Tomograms and a computed tomography scan again showed open apophyseal joints at L3-4, with a large osteophyte compromising the intervertebral foramina (see figure). Surgical removal of the osteophyte gave immediate relief.

\section{Comment}

Although pain in a nerve root distribution is sometimes encountered in ankylosing spondylitis, corresponding neurological abnormalities are rare and evidence of structural lesions affecting the nerve roots is usually lacking. ${ }^{2}$ Bony ankylosis of intervertebral foramina is not a feature of the disease $^{2}$ and root lesions are usually attributed to inflammatory changes in related structures or to vascular insufficiency.

In the case described here four instances of nerve root compression occurred, one in the cervical spine and three at the same level in the lumbar spine. Pain and parasthesiae in the nerve root distribution were the presenting features and were accompanied by neurological deficit. Large osteophytes arising from the posterior apophyseal joint and protruding forward into the corresponding intervertebral foramina were shown in each instance. The corresponding apophyseal joints at the two levels affected were unfused, in contrast to extensive ankylosis above and below.

We believe that prominent osteophytes arose from the apophyseal joints of the unfused segment as a result of the abnormal stresses imposed during movement. The osteophytic spurs were distinct from the spondylitic process.' Similarly, the bony protruberances at the anterior margins of the corresponding intervertebral joints appeared to be osteophytes rather than syndesmophytes.

Destructive changes at unfused segments in late ankylosing spondylitis have been described, ${ }^{3-5}$ and massive osteophytosis may occur during the healing of these areas. ${ }^{5}$ Nerve root compression due to encroachment on intervertebral foramina at unfused levels has not, however, been reported. There was no evidence of fracture or destructive lesions in our patient.

Marcos and Freiberger ${ }^{3}$ suggested immobilisation and promotion of complete ankylosis as the treatment of choice in destructive vertebral lesions. Our patient has had no recurrence of cervical nerve root compression since fusion, but he has had further problems at the L3-4 level, which was not fused surgically and is the last joint to remain mobile in his spine.

1 Thomas DJ, Kendall MJ, Whitfield AGW. Nervous system involvement in ankylosing spondylitis BrMed f 1974; i: 148-50.

2 Matthews WB. The neurological complications of ankylosing spondylitis. I neurol Sci 1968;6: $561-73$.

3 Marcos R, Freiberger RH. Vertebral destruction at unfused segments in late ankylosing spondylitis. Radiology 1969;93:251-6.

4 Cawley MID, Chalmer TM, Kellgren JH, Ball T. Destructive lesions of vertebral bodies in anyklosing spondylitis. Ann Rheum Dis 1972;3:345.

5 Dunn N, Preston B, Jones KL. Unexplained acute backache in longstanding ankylosing spondylitis. BrMed F 1985;291:1632-5.

(Accepted 21 May 1986)

University Department of Medicine, Bristol Royal Infirmary, Bristol BS2 8HW

$\mathrm{K}$ VEERAPEN, MB, MRCP, clinical assistant in rheumatology

P A DIEPPE, MD, FRCP, senior lecturer in rheumatology

Department of Neurosurgery, Frenchay Hospital, Bristol BS16 1LE

$R$ VEERAPEN, FRCS, $S N$, registrar in neurosurgery

H B GRIFFITH, FRCS, FRCP, senior consultant neurosurgeon

Correspondence to: Dr Paul Dieppe.

\section{Correction}

Prevalence of antibody to HTLV-III in haemophiliacs in the United Kingdom

In the Patients, methods, and results section of this short report (19 July, p 175) it was stated that " $20(60 \%)$ of 324 patients with haemophilia B who were tested were positive...." This should have read " $20(6 \%)$ of 324 patients with haemophilia B who were tested were positive." We apologise for this error. 